\title{
A Study on the Improvement of Nursing Interruption Risk by a Closed-Loop Management Model
}

\author{
Wen-Guang Zhang \\ Jia-Wei Liu \\ Su-Yun Yang \\ Qiao-Qian Wang \\ Chen-Xing Liu \\ Yao Li
}

'Department of Nursing, The First Hospital of Shanxi Medical University, Taiyuan, 030000, People's Republic of China; ${ }^{2}$ School of Nursing, Shanxi Medical University, Taiyuan, 030000, People's Republic of China; ${ }^{3}$ Department of Nuclear Medicine, The First Hospital of Shanxi Medical University, Taiyuan, 030000, People's Republic of China; ${ }^{4}$ Department of Hypertension, The First Hospital of Shanxi Medical University, Taiyuan, 030000, People's Republic of China
Correspondence: Su-Yun Yang Department of Nuclear Medicine, The First Hospital of Shanxi Medical University, Room 60I, Unit 8, Building I, No. 8 Wenyuan Lane, Yingze District, Taiyuan, 030000, People's Republic of China

Tel +86I36035I2029

Email syy_dr09sun@163.com
Objective: This study aimed to evaluate the effect of closed-loop management on nursing disruption risk.

Methods: Using a quasi-experimental research method, convenient sampling was used to extract 20 nurses working at our hospital as the research objects. The control group members were selected from January to March 2018 via the traditional method, and the experimental group members were selected from April to June 2018 via the closed-loop management method. At three months before and after the implementation of the management model, a self-designed quantitative test form and satisfaction questionnaire were used to analyze the frequency of nursing disruption events, the accuracy rate of doctors' advice, the average drug delivery time of the static distribution center, the implementation rate of personal digital assistant (PDA) code scanning, and the report rate of risk-outcome nursing disruption events. Results: After the implementation of the management model, the frequency of nursing disruptions and average drug delivery time of the static distribution center were significantly lower than before, and the differences were statistically significant $(\mathrm{p}<0.05)$. Moreover, the accuracy rate of doctors' advice, the implementation rate of PDA code scanning, and the reporting rate of risk-outcome nursing disruption events were significantly higher than before, and these differences were statistically significant as well $(\mathrm{p}<0.05)$.

Conclusion: The application of a closed-loop management model could significantly reduce the occurrence and optimize the outcomes of nursing disruption events and improve the work processes of medical care.

Keywords: closed-loop management, nursing interruption, risk control, personal digital assistant, PDA, management mode

\section{Introduction}

A nursing interruption is a sudden interruption that delays or distracts a nurse from delivering care to a patient at a specific time or in a specific role or environment. ${ }^{1}$ In recent years, the United States Joint Commission on the Accreditation of Medical Institutions, American Institute of Medicine, and American Institute of Health Services and Quality have noted that disruptive events can lead to inevitable medical errors. It has also been proven in Australia, Canada, Britain, Italy, and other developed countries that such events are closely correlated with medication errors. ${ }^{2,3}$ A previous study has revealed that nursing disruption events increase the incidence of nursing risk overall, the risk of process errors by $12.1 \%$, and the risk of clinical errors by $12.7 \%{ }^{4}$ In their study on nursing disruptions during drug 
administration, Odberg et $\mathrm{al}^{5}$ reveal that they mainly stem from patients, family members, and nursing colleagues and that the incidence of negative outcomes due to this is the highest in drug administration. Studies on nursing disruption events in drug delivery in the general surgery ward and drug medication in the digestive and endocrine departments have concluded that negative disruption events are predominant. ${ }^{6}$ At the time of most interruptions, nurses are primarily performing drug administration and are in direct contact with patients. During the 136 hours observed by Kalisch and Aeberselel, interruptions in treatment management increased the risk of errors by $60 \%{ }^{7}$ Kopp et al have reported that $40 \%$ of medication errors are due to errors and memory lapses, ${ }^{8}$ while Westbrook et al have shown that, in their study, $25 \%$ of 3177 drugs were administered with treatment errors, the likelihood of which more than doubled if there were four or more interruptions compared with no interruptions. ${ }^{9}$ Frequent interruptions interfere with nurses' attention and prospective memory and affect nursing outcomes. Powerful interruptions can cause recipients to forget prospective tasks and make it difficult for them to return to the execution state of their original tasks, increasing the risk of errors and posing a threat to patient safety.

Closed-loop management (CLM) was first applied in the field of automatic control and is a management method used to implement the concept of risk prevention. "Closed-loop" refers to the continuous improvement cycle of management and control, in which the output signal is used as part of the input, following the process of "decision-control-feedback-decision-feedback". ${ }^{10}$ Closed-loop management integrates a closed-loop system, closed management principle, management control, information system, and other principles. It not only focuses on forward-looking control but also considers the post-analysis, which organically combines the structure, process, and results to form the CLM. ${ }^{11}$ As an important achievement in the development of modern management science, CLM has become a common method to strengthen hospital medical quality management, improve medical quality, and standardize medical service behaviors. In recent years, closed-loop systems have been widely used in the medical field for clinical blood use, safe drug use, critical value management, and adverse event reporting, achieving good results. ${ }^{12,13}$ However, the application of CLM in nursing interruption risk management has not been reported either at home or abroad.
With the rapid development of medical technology, the expansion of nursing functions, and the high risk of nursing, disruptions to nurses' work are increasing, accompanied by unpredictable risks. ${ }^{14-16}$ Nursing disruption events seriously reduce nurses' work efficiency and may cause medical errors and threaten patient safety. ${ }^{17-19}$ Therefore, effectively managing these events is the core issue of this project. The CLM model aims to manage the risk outcomes of nursing disruption events by establishing control standards, evaluating the effectiveness of activities, correcting wrong means, and eliminating deviations from standards and plans among other comprehensive measures. Since 2018, through the implementation of the whole-process CLM model for nursing disruption events for risk outcomes at all levels of nursing quality (structure, process, results), the incidence of risk outcomes caused by such events has reduced. This study reports on the effects of CLM on the risk outcomes of nursing disruptions.

\section{Materials and Methods \\ Study Subjects and Setting}

A quasi-experimental research method was used to extract 20 nurses from our hospital as the research objects. As the clinical nursing posts in our hospital are set as "responsible" nursing posts (shifts A, P, and N) and auxiliary posts (7:00-12:00/15:00-18:00), convenience sampling was used to select three responsible nurses and one assistant nurse from each of the five studied departments using a personal digital assistant (PDA). There were 2 males and 18 females, with an average age of 34.6 years. Among them were five nurses, eight senior nurses, five supervisor nurses, and two co-chief superintendent nurses. Two had technical secondary school degrees, seven had associate degrees, nine had undergraduate degrees, and two had graduate degrees.

The traditional method was adopted from January to March 2018 to form the control group, and the CLM method was implemented from April to June 2018 to form the experimental group. At three months before and after the implementation of the management model, a self-designed quantitative test form and satisfaction questionnaire were used to analyze the frequency of nursing disruption events, the accuracy rate of doctors' advice, the average drug delivery time of the static distribution center, the implementation rate of PDA code scanning, and the reporting rate of riskoutcome nursing disruption events. 


\section{Implementation Method of the CLM Model}

The CLM model was applied at every level of the "structureprocess-result" quality management. An open management system was constructed as positive-feedback CLM: A) establishing control standards; B) evaluating the effectiveness of activities; and C) correcting wrong means to eliminate deviation from standards and plans. Strong excitement was generated for the system itself by improving the functions of the management system and efficiency, which is fundamental to ensuring nursing quality.

\section{Structure Level}

Control standards were designed to find the hidden nursing disruption events that lead to adverse risks to achieve the control objective (ie, to reduce their frequency and incidence), improve the creation of a nursing information system in our hospital, and use electronic mobile nursing equipment to ensure that responsible nurses complete all nursing work at the bedside. A project management and quality control team was established to monitor the hidden nursing disruption events, strengthen the construction of the ward without accompanying care, implement access control management, and provide security guards and paramedics to decrease the accompaniment rate to reduce the exogenous factors of disruptive events.

\section{Process Level}

The key points of the head nurse's rounds were adjusted via finding and controlling the hidden nursing disruption events that lead to risk outcomes as one of the indexes used to evaluate the head nurse's risk management ability. The fulltime nursing staff members of the doctor-patient communication office were responsible for handling negative disputes to provide the nurses with a quiet and orderly working environment. Moreover, 96 standard operation procedures of nursing quality management were formulated to guide and standardize the nursing work. For example, the CLM mode of blood transfusion was adopted. With this method, the medical staff used PDAs to read information and create electronic real-time records of the whole blood transfusion process, including the blood transfusion preparation ordered by doctors, bedside blood collection, blood sample submission, blood crossmatching in the hematology department, blood collection by nursing staff, blood infusion, and observation of adverse reactions. Closed-loop drug management was achieved with the help of the PDA mobile information system. The whole process of quick response code follow-up was as follows: Doctors issued medical orders after review, the pharmacy confirmed the concurrent drugs and, with the ward, completed the handover, and then, the nursing staff implemented the information for bedside drug delivery. The drug delivery process could be checked through the supervision system.

\section{Result Level}

Nursing disruptions that may have hidden risk outcomes were monitored; root cause analyses and system tracking were conducted to continuously improve the nursing quality.

Nursing CLM can effectively change traditional working modes and processes, effectively improve patients' medical experiences, and ensure nursing safety. It has the following advantages: (1) Patient identification is diversified. Through the application of quick response codes and mobile nurse workstations, identification methods are increased, the occurrence of human error is reduced, and zero errors occur in patient identification. (2) The whole life cycle of medical orders is realized, each link is accurately tracked and recorded, and responsibility is delegated to track the staff members, processes, scientific statistics, comprehensive analyses, practical operations, and individual corrections. (3) The whole process of nursing documentation is computerized, reducing manual writing or copying mistake. (4) Through the application of a mobile information system, nurses' working efficiency is improved, their workload can be accurately accounted for, and scientific performance management can be achieved.

\section{Data Acquisition Methods}

The research and control groups filled out a unified selfdesigned quantitative examination form designed to collect their data, and expert consultation was used to compile the satisfaction questionnaire on the application of the CLM mode. All original data were compiled by five graduate students who were strictly trained to master unified data collection and entry methods. The recorder went into the clinics to collect the nursing outcome data of the observed subjects three months before and after the implementation of the CLM mode from Monday to Friday at 8:00 18:00. The data were entered by two people to ensure authenticity and accuracy. The data were timely collected and sorted every day, timely modified and supplemented when misfiling occurred or missing data were found, and logic checked. A sampling check was repeated each week, and timely feedback on the supervision results was provided for error correction and improvement to ensure the accuracy and integrity of the data. To avoid subjective bias, 
a blind method was adopted for the input personnel, and the researcher himself did not participate in the data entry.

\section{Observation Indexes}

The main observation indexes included the frequency of nursing disruption events, the accuracy rate of doctors' advice, the average drug delivery time of the static distribution center, the implementation rate of PDA code scanning, the reporting rate of risk-outcome nursing disruption events, and the nurses' job satisfaction rating.

\section{Statistical Analysis}

The study data were analyzed using statistical software SPSS 25.0. The measurement data were expressed as the mean \pm standard deviation. The count data were expressed as percentages (\%). The normality was tested via the $\mathrm{W}$-test. The homogeneity of variance was tested using the F-test. Intergroup comparison was conducted using a $t$-test. The non-normally distributed means of multiple samples or normally distributed means of multiple samples with heterogeneity of variance were compared using a nonparametric test. The count data were compared using a chi-square test. A p value $<0.05$ was considered statistically significant.

\section{Ethical and Legal Considerations}

The present study met the requirements of the Declaration of Helsinki of the World Medical Association. The ethics committee of the First Hospital of Shanxi Medical University reviewed and approved this study. As this research did not require any patient-related interventions or experiments, patient informed consent was not required. Prior to completing the questionnaire, all nurse participants gave their informed consent, confirming that they knew their participation was voluntary and anonymous, that they could withdraw at any time, and that their data would be kept completely confidential and stored and analyzed on a secure computer for research purposes only.

\section{Results}

\section{Comparison of the Frequency of Nursing Disruptions Before and After CLM Implementation}

After the implementation of the CLM mode, the frequency of nursing interruptions in the experimental group (1764 times) was significantly lower than that in the control group (2340 times) during the three months, and the difference was statistically significant $\left(\chi^{2}=11.177, \mathrm{p}=0.025<0.05\right)$ (Table 1 ).

The sources of the nursing interruption events before and after the implementation are shown in Table 2.

\section{Comparison of the Accuracy Rate of Doctors' Advice Before and After CLM Implementation}

After the implementation, the accuracy rate of doctors' advice in the experimental group (95\%) was higher than that in the control group (75\%), and the difference was statistically significant $\left(\chi^{2}=17.316, \mathrm{p}<0.001\right)$ (Table 3$)$.

\section{Comparison of the Average Drug Delivery Time of Static Distribution Center Before and After CLM Implementation}

After the implementation, the average drug delivery time of the static distribution center of the experimental group $(41.42 \pm 5.17 \mathrm{~min})$ was significantly shorter than that of

Table I Comparison of the Frequency of Nursing Disruption Before and After Implementation

\begin{tabular}{|c|c|c|c|c|c|c|c|}
\hline Time & Department I & Department 2 & Department 3 & Department 4 & Department 5 & $\chi^{2}$ value & $P$ value \\
\hline Before implementation & 460 & 500 & 390 & 475 & 515 & 11.177 & 0.025 \\
\hline After implementation & 300 & 360 & 356 & 364 & 384 & & \\
\hline
\end{tabular}

Table 2 The Sources of Nursing Disruption Events Before and After Implementation

\begin{tabular}{|l|l|l|l|l|l|l|l|}
\hline Time & Environment & $\begin{array}{l}\text { Nurse } \\
\text { Colleagues }\end{array}$ & $\begin{array}{l}\text { Nurses } \\
\text { Themselves }\end{array}$ & Doctors & $\begin{array}{l}\text { Other Health } \\
\text { Workers }\end{array}$ & $\begin{array}{c}\chi^{2} \\
\text { value }\end{array}$ & $\begin{array}{l}\boldsymbol{p} \text { value } \\
\text { Before implementation }\end{array}$ \\
$\begin{array}{l}\text { After implementation } \\
259\end{array}$ & 390 & 402 & 361 & 430 & 16.467 & 0.006 \\
\hline
\end{tabular}


Table 3 Comparison of the Correct Rate of Doctor's Advice Before and After Implementation (n/\%)

\begin{tabular}{|l|l|l|c|c|}
\hline Time & $\begin{array}{l}\text { Number of } \\
\text { Doctor's } \\
\text { Advice }\end{array}$ & $\begin{array}{l}\text { Correct } \\
\text { Rate }\end{array}$ & $\begin{array}{c}\chi^{2} \\
\text { value }\end{array}$ & $p$ value \\
\hline $\begin{array}{l}\text { Before implementation } \\
\text { After implementation }\end{array}$ & 80 & 70 & 17.316 & $<0.001$ \\
\hline
\end{tabular}

the control group $(57.53 \pm 15.73 \mathrm{~min})$, and the difference was statistically significant $\left(\chi^{2}=6.087, \mathrm{p}<0.001\right)$ (Table 4$)$.

\section{Comparison of the Standard Rate of Process Implementation Before and After CLM Implementation}

After the implementation, the standard rate of process implementation in the experimental group (95\%) was significantly higher than that in the control group (75\%), and the difference was statistically significant $\left(\chi^{2}=12.549, p=0.001\right)$ (Table 5).

\section{Comparison of the Implementation Rate of PDA Code Scanning Before and After CLM Implementation}

From July to December 2018, the implementation rate of PDA code scanning in our hospital after the CLM implementation was investigated. The results showed that the rate in infusion, injection, oral administration, skin testing, and other important tasks after CLM implementation was significantly higher $(92 \%)$ than that before implementation (69\%), and the difference was statistically significant $\left(\chi^{2}=9975.106, p=0.000\right)$ (Table 6).

Table 4 Comparison of the Average Drug Delivery Time of Static Distribution Center Before and After the Implementation (min)

\begin{tabular}{|l|l|l|l|l|}
\hline Time & $\begin{array}{l}\text { Drug } \\
\text { Delivery } \\
\text { Times }\end{array}$ & $\begin{array}{l}\text { Average } \\
\text { Drug Delivery } \\
\text { Time }\end{array}$ & t value & $\boldsymbol{p}$ value \\
\hline $\begin{array}{l}\text { Before implementation } \\
\text { After implementation }\end{array}$ & 36 & $57.53 \pm 15.73$ & 6.087 & $<0.001$ \\
\hline
\end{tabular}

\section{Comparison of the Reporting Rate of} Risk-Outcome Nursing Disruption Events Before and After CLM Implementation

After the implementation, the reporting rate of falls/falling out of bed in the experimental group (37.4\%) was higher than that in the control group (22.9\%). Similarly, the reporting rate of pressure sores was higher in the experimental group $(17.8 \%)$ than in the control group (14.6\%), but the reporting rate of administration errors was lower $(24.3 \%$ and $51.0 \%$, respectively). Moreover, the reporting rate of unplanned extubation in the experimental group (20.1\%) was higher than that in the control group $(11.5 \%)$. The differences were statistically significant $\left(\chi^{2}=16.115, \mathrm{p}=0.001\right)($ Table 7).

\section{Comparison of Nurse/Patient Satisfaction Rate (\%) Before and After Implementation}

The results of this study showed that after the implementation of the CLM mode, the patient satisfaction rate rose from $92.63 \%$ to $98.95 \%$, an increase of $6.32 \%$. Moreover, the nurse job satisfaction rate rose from $80.26 \%$ to $87.55 \%$, an increase of $7.29 \%$.

\section{Discussion}

\section{The Significance of Project Management for Nursing Disruptions}

Ensuring patient safety is the most basic requirement of global public health services as well as the most basic element to improve the quality of medical and nursing services. ${ }^{20,21}$ Due to the high risk of nursing itself, the rapid development of medical technology, the transformation of nursing, the expansion of nursing functions, and the widespread application of new nursing technologies and products in clinical practice, nursing disruptions are increasing, and unpredictable nursing risks remain present.

Disrupting nurses' work and increasing their risk of mistakes can have catastrophic consequences. Nursing risk and nursing quality are two sides of the same coin, and risk management could be an effective way to improve the latter. Therefore, an in-depth analysis on the risk factors of the

Table 5 Comparison of the Standard Rate of Process Implementation Before and After Implementation (n/\%)

\begin{tabular}{|l|l|l|c|c|}
\hline Time & Implementation Times & Standard Rate & $\chi^{2}$ value & p value \\
\hline Before implementation & 80 & 75 & 12.549 & 0.001 \\
After implementation & 80 & 95 & & \\
\hline
\end{tabular}


Table 6 Comparison of the Implementation Rate of PDA Code Scanning Before and After Implementation (n/\%)

\begin{tabular}{|l|l|l|l|l|}
\hline Time & Code Scanning Times & Implementation Rate (\%) & $\chi^{2}$ value & $p$ value \\
\hline Before implementation & 58,958 & 69 & 9975.106 & $<0.001$ \\
After implementation & 59,638 & 92 & & \\
\hline
\end{tabular}

Table 7 Comparison of the Reporting Rate of Risk-Outcome Nursing Disruption Events Before and After Implementation (n/\%)

\begin{tabular}{|l|l|l|l|l|l|l|l|}
\hline Time & $\mathbf{n}$ & $\begin{array}{l}\text { Falls/Falling } \\
\text { Out of Bed }\end{array}$ & $\begin{array}{l}\text { Pressure } \\
\text { Sores }\end{array}$ & $\begin{array}{l}\text { Administration } \\
\text { Error }\end{array}$ & $\begin{array}{l}\text { Unplanned } \\
\text { Extubation }\end{array}$ & $\chi^{2}$ value & $\boldsymbol{p}$ value \\
\hline $\begin{array}{l}\text { Before implementation } \\
\text { After implementation }\end{array}$ & 96 & $\begin{array}{l}22(22.9) \\
107\end{array}$ & $\begin{array}{l}14(14.6) \\
19(17.8)\end{array}$ & $\begin{array}{l}49(51.0) \\
26(24.3)\end{array}$ & $\begin{array}{l}\text { II (II.5) } \\
22(20.1)\end{array}$ & 16.115 & 0.001 \\
\hline
\end{tabular}

entire process before, during, and after a disruption event should be conducted to better avoid the risks and improve the nursing quality. ${ }^{5,6,22,23}$ It is important to establish a complete nursing safety CLM method to reduce the incidence of nursing interruptions. This study's investigation results showed that the nursing process CLM model could effectively guarantee nursing safety and risk management, achieve the security work forward, turn terminal care quality supervision for the link and the continuous improvement of quality control and routine, do dynamic assessment unsafe factors, make up for the loopholes in time, improve protection systems, and effectively reduce safety risks to promote nurse safety. Research on nursing disruptions in China is in its infancy, so Chinese scholars should intervene and manage these interruptions to further promote nurse and patient safety.

\section{The Scientific Nature of the Application of the CLM Model in the Intervention of Nursing Disruption Events Leading to \\ Hidden Risk Outcomes}

The CLM model forms a continuous closed loop regarding the management of a system and its subsystems and keeps the system activities in balance. Regarding the objective reality of change, sensitive, accurate, and powerful informational feedback should be provided, and corresponding changes should be made to timely resolve disputes and problems. Decision, control, feedback, re-decision, re-control, re-feedback to improve continuously throughout the cycle.

The project belongs to the field of hospital management. With patient safety as the ultimate goal, the CLM model was used to control and eliminate the risks of nursing disruptions. In the early stage, risk management theory was used to establish an indicator of the nurses' ability to identify patient risks and the ability they should have as nursing managers, after training, based on the positive-feedback CLM model. This was meant to improve and control the frequency of nursing disruption events that could produce $80-90 \%$ risk outcomes to optimize the patient outcomes and ensure nursing quality. ${ }^{24-26}$

The "Plan Outline of National Medical and Health Service System (2015-2020)" explicitly proposed that China would carry out the Healthy China Cloud Service Plan, promote the application of healthy big data, and improve the service ability and management level. By 2020, China was to achieve informationized big data health management. The research and design ideas of this project conformed to the general trends of contemporary social development.

The central task of hospital management is ensuring the safety of every patient. The decision-making and design of nursing informationization are conducted to ensure patient safety, facilitate service processes, improve work efficiency, and increase the standard of management. At present, there are few studies on the risk management of nursing disruptions in China. Based on a four-year research series on hospital nursing risk management, our hospital also performed two years of research on the risk outcome management of nursing disruptions, the foundation of which was solid.

This project combined hospital nursing informationization system creation and quality management process reengineering. The former considers the risk outcomes of nursing disruption events and implements the entire process of CLM for such events in nursing quality management module and online quality monitoring design in China.

Nurses are always with patients during the process of medical treatment; therefore, they monitor the patients' conditions in real time. However, the traditional nursing 
management model lacks mechanisms of analysis, summary, rectification, or effect re-feedback. The frequency of nursing disruption events can be as high as 12-14 times/ hour. The positive-feedback CLM model can avoid the omission of nursing work and compensate for a lack of nursing. Without missing a step of the entire nursing process, a complete closed loop cannot be formed. A combination of the internet, an informationization nursing system, and risk management theory to reduce the nursing disruption events that cause risk outcomes can circumvent nursing risks and reduce adverse events.

\section{Development Space of the Combination of CLM and Informationization Construction to Intervene in Nursing Disruptions}

At present, the informatization creation of our hospital has passed the Healthcare Information and Management Systems Society level six and interconnection level four review standards, and the nursing quality informationization system of all 73 nursing units has been put online. Based on the informationization creation, in this study, the CLM model was applied to the management of nursing disruption events. These effective intervention measures reduced the frequency of nursing disruption events, extend the interval between their occurrence, optimize their outcomes, and reduce their frequency from $12-14$ to 9.8 times/hour, significantly improving nurses' ability to handle and control the risk of disruptions. The accuracy rate of doctors' advice, standard rate of process implementation, implementation rate of PDA code scanning for intravenous infusion, oral administration, skin testing, and injection in the static distribution center were improved, while the average time of drug delivery of the static distribution center was reduced. Moreover, the patient satisfaction rate increased from $78.9 \%$ to $93.3 \%$. The quality and efficiency of nursing work improved, and the nurses' self-efficacy was enhanced. Furthermore, the intervention enabled managers to handle drug administration disruption events more comprehensively, reducing their occurrence and improving the management efficiency of patient safety. Nurse managers and nurses were able to deepen their knowledge of nursing disruption events and create a scientific treatment plan for such events to avoid nursing risks and ensure patient safety. Finally, the nurses' satisfaction rate with the nursing work environment was improved.
This study had the following limitations: Firstly, the results revealed that the implementation of the CLM model achieved certain results, but no in-depth analysis of the risks associated with nursing disruption events was performed. Second, this study did not design detailed management content or a standardized operation process based on the informationization creation. Therefore, this project took up obvious research space in the application and exploration of the CLM model to the risk outcome management of nursing disruption events. The next study will effectively research and further discuss the CLM model of nursing disruption events to ensure patient safety, improve the quality and efficiency of nursing, and reduce nurses' burden based on improvement of the mobile information system.

In conclusion, the application of the CLM model could significantly reduce the occurrence and optimize the outcomes of nursing disruption events, improve the working processes of medical care, and improve nurses' job satisfaction rate.

\section{Acknowledgments}

This study was supported by 2018 Shanxi Province Key Research and Development Plan (Social Development Field, No. 201803D31105).

\section{Disclosure}

All of the authors had no any personal, financial, commercial, or academic conflicts of interest separately.

\section{References}

1. Xie J-F, Ding S-Q, Zeng S-N, Yi Q-F, Qin C-X, Zhou J-D. Nursing interruptions: a concept analysis and implications. Chin J Nurs. 2013;48(02):175-178. doi:10.3761/j.issn.0254-1769.2013.02.027

2. Jett QR, George JM. Work interrupted: a closer look at the role of interruptions in organizational life. Acad Manage Rev. 2003;28 (3):494-507. doi:10.2307/30040736

3. ISMP Canada. Fluorouracil incident root cause analysis. April 30, 2007 (formatted for posting on the Alberta Cancer Board Web site on May 23, 2007). Available from: www.cancerboard.ab.ca/NR/rdonlyres/2FB61BC470CA-4E58-BDE1-1E54797BA47D/0/Fluor-ouracillncidentMay2007. pdf. Accessed July 5, 2021.

4. Hopkinson SG, Jennings BM. Interruptions during nurses' work: a state-of-the-science review. Res Nurs Health. 2013;36(1):38-53. doi:10.1002/nur.21515

5. Odberg KR, Saetre Hansen B, Aase K, Wangensteen S. Medication administration and interruptions in nursing homes: a qualitative observational study. J Clin Nurs. 2018;27(5-6):1113-1124. doi:10.1111/ jocn. 14138

6. Cole G, Stefanus D, Gardner H, Levy MJ, Klein EY. The impact of interruptions on the duration of nursing interventions: a direct observation study in an academic emergency department. BMJ Qual Saf. 2016;25(6):457-465. doi:10.1136/bmjqs-2014-003683 
7. Kalisch BJ, Aebersold M. Interruptions and multitasking in nursing care. Jt Comm J Qual Patient Saf. 2010;36(3):126-132. doi:10.1016/ S1553-7250(10)36021-1

8. Kopp BJ, Erstad BL, Allen ME, Theodorou AA, Priestley G. Medication errors and adverse drug events in an intensivecare unit: direct observation approach for detection. Crit Care Med. 2006;34:415-425. doi:10.1097/01.CCM.0000198106.54306.D7

9. Westbrook JI, Coiera E, Dunsmuir WT, et al. The impact of interruptions on clinical task completion. Qual Saf Health Care. 2010;19:284-289. doi:10.1136/qshc.2009.039255

10. Shao L-L, Zhang Y, Shi J-M, Zhu M, Ding J-M. Research on the application value of closed-loop management modein the risk management of patients with artificial airwayin respiratory monitoring. Cardiovasc Dis Electron J Integr Trad Chin West Med. 2020;8 (32):23-26. doi:10.16282/j.cnki.cn11-9336/r.2020.32.013

11. Xi X, He P, Huang S. Medical safety adverse events management based on closed-loop management mode. Chin Health Qual Manage. 2018;25(1):73-75. doi:10.13912/j.cnki.chqm.2018.25.1.25

12. Hu S-Z. Application of closed-loop information system construction in nursing management of critical patients in ICU. Contemp Med. 2017;23(30):168-170. doi:10.3969/j.issn.1009-4393.2017.30.081

13. Lu C, Yi-jun J, Xie S. Construction and application of the closed-loop process management of medical examination. Chin Digit Med. 2020;15(03):41-43. doi:10.3969/j.issn.1673-7571.2020.03.013

14. Sassaki RL, Perroca MG. Interruptions and their effects on the dynamics of the nursing work. Rev Gaucha Enferm. 2017;38(2): e67284. doi:10.1590/1983-1447.2017.02.67284

15. Dante A, Andrigo I, Barone F, et al. Occurrence and duration of interruptions during nurses' work in surgical wards. J Nurs Care Qual. 2016;31(2):174-182. doi:10.1097/NCQ.0000000000000159

16. Hayes C, Jackson D, Davidson PM, Daly J, Power T. Calm to chaos: engaging undergraduate nursing students with the complex nature of interruptions during medication administration. J Clin Nurs. 2017;26 (23-24):4839-4847. doi:10.1111/jocn.13866

17. Walter SR, Li L, Dunsmuir WT, Westbrook JI. Managing competing demands through task-switching and multitasking: a multi-setting observational study of 200 clinicians over 1000 hours. BMJ Qual Saf. 2014;23(3):231-241. doi:10.1136/bmjqs-2013-002097
18. Mamykina L, Carter EJ, Sheehan B, Stanley Hum R, Twohig BC, Kaufman DR. Driven to distraction: the nature and apparent purpose of interruptions in critical care and implications for HIT. J Biomed Inform. 2017;69:43-54. doi:10.1016/j.jbi.2017.01.015

19. Prates Dde O, Silva AE. Interruptions of activities experienced by nursing professionals in an intensive care unit. Rev Lat Am Enfermagem. 2016;24:e2802. doi:10.1590/1518-8345.0997.2802

20. Spooner A. Response to letter to the editor: "measurement of the frequency and source of interruptions occurring during bedside nursing handover in the intensive care unit: an observational study". Aust Crit Care. 2017;30(2):58. doi:10.1016/j.aucc.2016.11.004

21. Craker NC, Myers RA, Eid J, et al. Nursing interruptions in a trauma intensive care unit. J Nurs Adm. 2017;47(4):205-211. doi:10.1097/ NNA.0000000000000466

22. Sørensen EE, Brahe L. Interruptions in clinical nursing practice. J Clin Nurs. 2013;23(9-10):1274-1282. doi:10.1111/jocn.12329

23. Spooner A, Chaboyer W, Aitken L. Using the Plan-Do-Study-Act cycle to manage interruptions during nursing team leader handover in the intensive care unit: quality improvement project. Aust Crit Care. 2018;31(2):132. doi:10.1016/j.aucc.2017.12.056

24. Spooner AJ, Corley A, Chaboyer W, Hammond NE, Fraser JF. Measurement of the frequency and source of interruptions occurring during bedside nursing handover in the intensive care unit: an observational study. Aust Crit Care. 2015;28(1):19-23. doi:10.1016/j. aucc.2014.04.002

25. Hillel G, Vicente KJ. Nursing interruptions in a post-anesthetic care unit: a Field Study. Proc Hum Factors Ergon Soc Annu Meet. 2003;47(12):1443-1447. doi:10.1177/154193120304701214

26. Dhib-Jalbut S, Markowitz C, Patel P, Boateng F, Rametta M. The combined effect of nursing support and adverse event mitigation on adherence to interferon beta-1b therapy in early multiple sclerosis: the START Study. Int J MS Care. 2012;14(4):198-208. doi:10.7224/ 1537-2073-14.4.198
Risk Management and Healthcare Policy

\section{Publish your work in this journal}

Risk Management and Healthcare Policy is an international, peerreviewed, open access journal focusing on all aspects of public health, policy, and preventative measures to promote good health and improve morbidity and mortality in the population. The journal welcomes submitted papers covering original research, basic science, clinical \& epidemiological studies, reviews and evaluations,

\section{Dovepress}

guidelines, expert opinion and commentary, case reports and extended reports. The manuscript management system is completely online and includes a very quick and fair peer-review system, which is all easy to use. Visit http://www.dovepress.com/testimonials.php to read real quotes from published authors. 